\title{
Endoplasmic reticulum stress induced in motor neurons by transient spinal cord ischemia in rabbits
}

\author{
Masahiro Sakurai, MD, PhD, ${ }^{a}$ Goro Takahashi, MD, PhD, ${ }^{b}$ Koji Abe, MD, PhD, ${ }^{\text {e }}$ Takashi Horinouchi, MD, PhD, \\ Yasuto Itoyama, MD, $\mathrm{PhD}{ }^{\mathrm{c}}$ and Koichi Tabayashi, MD, $\mathrm{PhD}^{\mathrm{b}}$
}

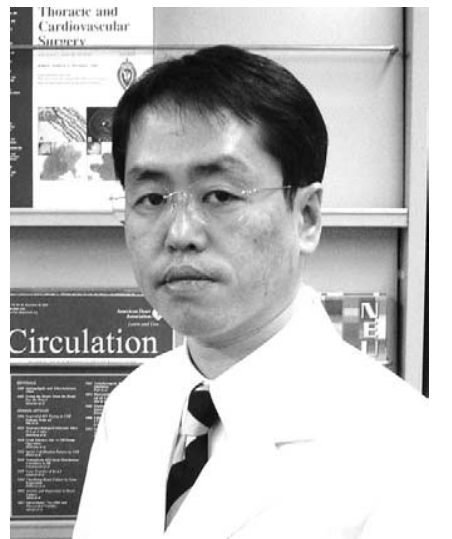

Dr Sakurai
From the Department of Cardiovascular Surgery, National Hospital Organization

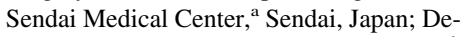
partments of Cardiovascular Surgery, ${ }^{\mathrm{b}}$ Neurology, ${ }^{\mathrm{c}}$ and Anesthesiology, ${ }^{\mathrm{d}}$ Tohoku University Graduate School of Medicine, Sendai, Japan; and Department of Neurology, Okayama University Graduate School of Medicine, ${ }^{\mathrm{e}}$ Okayama, Japan.

This study is partially supported by a grant from the Japan Foundation of Cardiovascular Research.

Received for publication Oct 14, 2004; revisions received Dec 3, 2004; accepted for publication Jan 5, 2005.

Address for reprints: Masahiro Sakurai, $\mathrm{MD}, \mathrm{PhD}$, Department of Cardiovascular Surgery, National Hospital Organization Sendai Medical Center, 2-8-8, Miyagino, Miyagino-ku, Sendai, 983-8520 Japan (E-mail: sakuraim@mail.tains.tohoku.ac.jp).

J Thorac Cardiovasc Surg 2005;130:640-5

$0022-5223 / \$ 30.00$

Copyright (C) 2005 by The American Association for Thoracic Surgery

doi:10.1016/j.jtcvs.2005.01.007
Objective: The mechanism of spinal cord injury has been thought to be related to the vulnerability of spinal motor neuron cells against ischemia. However, the mechanisms of such vulnerability are not fully understood. Because we previously reported that spinal motor neurons were probably lost as the result of programmed cell death, we investigated a possible mechanism of neuronal death by immunohistochemical analysis for Grp78 and caspase12.

Methods: We used a rabbit spinal cord ischemia model with a balloon catheter. The spinal cord was removed at 8 hours or 1,2, or 7 days after 15 minutes of transient ischemia. Histologic changes were studied with hematoxylin-eosin staining. Western blot analysis for Grp78 and caspase12, temporal profiles of Grp78 and caspase12 immunoreactivity, and double-label fluorescence immunocytochemical studies were performed.

Results: The majority of motor neurons were preserved for 2 days but were selectively lost at 7 days of reperfusion. Western blot analysis revealed scarce immunoreactivity for Grp78 and caspase12 in the sham-operated spinal cords. However, immunoreactivity for Grp78 and caspase 12 became apparent at 8 hours after transient ischemia, which returned to the baseline level at 1 day. Double-label fluorescence immunocytochemical study revealed that both Grp78 and caspase 12 were positive at 8 hours of reperfusion in the same motor neurons that eventually die.

Conclusion: This study demonstrated that immunoreactivities for both Grp78 and caspase 12 were induced in the same motor neuron that eventually dies. These results suggest that endoplasmic reticulum stress was induced in motor neurons by transient spinal cord ischemia in rabbits.

$\mathrm{S}$ pinal cord injury after a successful operation of thoracic aorta is a disastrous complication in humans. The reported incidences of paraplegia range from $2.9 \%$ to $23 \%^{1}$ in operations on the thoracic aorta. The cause of acute spinal cord dysfunction is believed to be the ischemic damage incurred during crossclamping. Ischemia can occur as the result of permanent exclusion of the essential intercostal arterial blood supply to the spinal cord or temporary interruption of blood flow to the spinal cord. ${ }^{2}$ However, patients undergoing thoracic aneurysm repair who awake with no neurologic deficit immediately after the operation may eventually have paraplegia. ${ }^{3,4}$ However, the exact mechanism of such delayed vulnerability is not fully understood. In a rabbit spinal cord ischemia model, we reported delayed and selective motor neuron death after transient ischemia. ${ }^{5}$ Furthermore in this model, we reported that delayed and selective motor neuron death was greatly associated with activated apoptotic signals. ${ }^{5}$

There are 2 major pathways for apoptosis induction: (1) the extrinsic pathway, which is activated by plasma membrane death receptor ligation, and (2) the intrinsic 
pathway, in which release of cytochrome $\mathrm{c}$ from mitochondria and activation of caspase 9 are implicated. ${ }^{6}$ In delayed neuronal death, the intrinsic pathway plays an important role, and the mitochondrial injury mechanism has been extensively investigated in the ischemic model. ${ }^{7}$ However, it has become clear that not only mitochondria but also other organelles, such as the endoplasmic reticulum (ER), Golgi apparatus, and lysosomes, are also involved in the intrinsic pathway of apoptosis. ${ }^{8,9}$

The ER is an organelle that plays an important role in the maintenance of intracellular calcium homeostasis and proper folding of newly synthesized secretory and membranous proteins. ${ }^{10}$ This subcellular organelle is sensitive to cellular stress. In response to cellular stress, such as glucose deprivation, calcium depletion in ER, and exposure to free radicals, unfolded proteins accumulate within ER, and several signaling pathways, designated as the unfolded protein response, are initiated to cope with this unfavorable situation. ${ }^{11,12}$ One major pathway of unfolded protein response is the suppression of most protein translations through the down-regulated function of eukaryotic initiation factors 2 and 4 by PKR-like ER eukaryotic initiation factor- $2 \alpha$ kinase, an ER-resident kinase. ${ }^{11,12}$ This pathway is likely to prevent further accumulation of unfolded proteins. Another pathway is the up-regulated expression of ER-localized molecular chaperons, such as Grp78 and Grp94, which contribute to repair unfolded proteins. ${ }^{11,12}$ Moreover, it has been reported that several cell death-inducing pathways are set in motion subsequent to the cellular stress that affects ER, collectively known as ER stress. ${ }^{11,12}$ Accumulating evidence shows that ER stress plays an important role in the mechanisms underlying ischemia-reperfusion neuronal damage. Nevertheless, the implications of the ER stressinduced cell death pathways remain elusive. Caspase12, which was identified as the first ER-associated member of the caspase family, is activated by ER stress, such as treatment with tunicamycin and thapsigargin, and this novel caspase is regarded as a representative molecule implicated in the cell death-executing mechanisms relevant to ER stress. ${ }^{13}$ We hypothesize that motor neuron cells eventually dying in this model of acute spinal cord ischemia demonstrate prior induction of Grp78 and caspase12. Thus, we examined the induction of Grp78 and caspase 12 in motor neurons after transient spinal cord ischemia.

\section{Materials and Methods \\ Animal Models}

During the experiment, the animals were treated in accordance with the Declaration of Helsinki and the guiding principles in the care and use of animals. Also, the experimental and animal care protocol was approved by the animal care committee of Tohoku University School of Medicine.

Twenty-eight Japanese domesticated white rabbits weighing 2 to $3 \mathrm{~kg}$ were used in this study. The rabbits were divided into 2 groups: a 15-minute ischemia group and a sham control group. Anesthesia was induced with intramuscular administration of ketamine at a dose of $50 \mathrm{mg} / \mathrm{kg}$ and maintained with $2 \%$ halothane inhalation. A $5 \mathrm{~F}$ pediatric thermodilution catheter (405, B. Braun Melsungen AG, Melsungen, Germany) was inserted through a femoral artery and advanced $15 \mathrm{~cm}$ forward into the abdominal aorta. Preliminary investigations by laparotomy confirmed that the balloon in the distal end of the thermodilution catheter was positioned 0.5 to $1.5 \mathrm{~cm}$ just distal to the left renal artery. During the experiment, aortic pressures were continuously monitored both at the proximal and distal positions of the balloon. When the balloon of the thermodilution catheter was inflated in the abdominal aorta, the systemic blood pressure of the rabbits did not change. The arterial pressure distal to the inflated balloon decreased to approximately zero, and no pulsation was recorded. On deflation of the balloon, systemic blood pressure of this portion decreased for 15 minutes and then returned to the normal level (data not shown). Body temperature was monitored with a rectal thermometer and maintained at $37^{\circ} \mathrm{C}$ with a heating pad during surgery and subsequent ischemia. Animals were allowed to recover at ambient temperature and were sacrificed with deep anesthesia of sodium pentobarbital $(100 \mathrm{mg} / \mathrm{kg}$ intravenously) at 8 hours or 1,2 , or 7 days after reperfusion ( $\mathrm{n}=5$ at each time point). In the sham control group, animals were sacrificed at 8 hours $(n=3)$ or 7 days $(n=5)$ of reperfusion after insertion of the catheter into the abdominal aorta without inflating the balloon. Immediately after the animals were sacrificed, spinal cords were quickly removed with a 1-mL syringe plunger. The tissue samples for Western blot analysis and immunohistochemical studies were frozen in powdered dry ice and stored at $80^{\circ} \mathrm{C}$. The samples for histology were fixed by immersion in $4 \%$ paraformaldehyde in $0.1 \mathrm{~mol} / \mathrm{L}$ phosphate buffer and then stored at $4^{\circ} \mathrm{C}$ for 1 week; they were then cut transversely at approximately the L2 or L3 level and finally embedded in paraffin.

\section{Neurologic Assessment}

Neurologic function was observed at 2 days and at 7 days after the procedure. Animals were classified according to a 5-point scale based on the method of Johnson and colleagues ${ }^{13 a}: 0=$ hind-limb paralysis; 1 = severe paraparesis; 2 = functional movement, no hop; 3 = ataxia, disconjugate hop; $4=$ minimal ataxia; and $5=$ normal function. Two individuals without knowledge of the treatment independently graded neurologic function.

\section{Histologic Study}

To see the pathologic changes of the spinal cord after ischemia, we performed hematoxylin-eosin staining with a set of sections that were examined by light microscopy. The number of intact large motor neuron cells in the ventral gray matter region was counted in 5 sections per animals. An observer, unaware of animal group and neurologic outcome, examined each slide $(\times 100)$. With hematoxylin-eosin staining, the cells were considered "dead" if the cytoplasm was diffusely eosinophilic and "viable" if the cells demonstrated basophilic stippling (ie, contained Nissl substance).

\section{Western Blot Analysis}

To investigate changes of Grp78 and caspase12 expression, we performed Western blot analysis. The tissue samples were homog- 
enized in a lysis buffer $(0.1 \mathrm{~mol} / \mathrm{L} \mathrm{NaCl}, 0.01 \mathrm{~mol} / \mathrm{L}$ Tris- $\mathrm{HCl}, \mathrm{pH}$ 7.5, $1 \mathrm{mmol} / \mathrm{L}$ EDTA, and $1 \mu \mathrm{g} / \mathrm{mL}$ aprotinin), and then the homogenates were centrifuged at $7000 \mathrm{~g}$ for 15 minutes at $4{ }^{\circ} \mathrm{C}$. The supernatants were used as protein samples. Assays to determine the protein concentration of the supernatants were subsequently performed by comparing the samples with a known concentration of bovine serum albumin with the use of the BCA protein assay reagent kit no. 23225 (Pierce, Rockford, Ill). Sodium dodecyl sulfate (SDS)-polyacrylamide gel electrophoresis was performed in a $10 \%$ polyacrylamide gel under nonreducing conditions. In brief, protein samples were boiled at $100^{\circ} \mathrm{C}$ in $2.5 \%$ SDS and $5 \%$ $\beta$-mercaptoethanol, and lysates equivalent to $20 \mu \mathrm{g}$ of protein from each sample were run on the gel for 90 minutes at $20 \mathrm{~mA}$, together with a size marker (Rainbow colored protein; Amersham, Buckinghamshire, United Kingdom). The electrophoresis running buffer contained $25 \mathrm{mmol} / \mathrm{L}$ Tris base, $250 \mathrm{mmol} / \mathrm{L}$ glycine, and $0.1 \%$ SDS. The proteins on the gel were then transferred to a polyvinylidene fluoride membrane (Micron Separations Inc, Westboro, Mass) with a transfer buffer consisting of $48 \mathrm{mmol} / \mathrm{L}$ Trisbase, $39 \mathrm{mmol} / \mathrm{L}$ glycine, $0.4 \%$ SDS, and $20 \%$ methanol.

After the transfer, the membranes were placed in $1 \%$ powdered milk in phosphate-buffered saline (PBS) to block nonspecific binding. Then they were incubated with primary antibodies at 1:1000 dilution for 20 hours at $4^{\circ} \mathrm{C}$. The primary antibodies used were goat polyclonal anti-Grp78 antibody (SC-1050; Santa Cruz Biotechnology Inc, Santa Cruz, Calif) and mouse monoclonal anti-caspase 12 antibody (SC-21747; Santa Cruz Biotechnology Inc). After the membranes were washed in PBS, they were incubated with horseradish peroxidase-conjugate antigoat immunoglobulin (Ig)-G (AP180P; Chemicon International, Inc, Temecula, Calif) and horseradish peroxidase-conjugate antimouse IgG (AP192P; Chemicon International, Inc) at 1:1000 dilution in PBS for 90 minutes, respectively. The blots were developed with the electrochemiluminescence detection method (RPN2106; Amersham Pharmacia Biotech, Tokyo, Japan). To ascertain specific binding of the antibody for the protein, another membrane was stained in a similar way without the primary antibody. The images of Western blot study were quantified by plotting a 2-dimensional densitogram with the image analysis program NIH Image, version 1.63 (Research Services Branch, National Institute of Mental Health, National Institutes of Health).

\section{Grp78 and Caspase12 Immunocytochemistry}

We also performed an immunohistochemical study to investigate changes of expression of Grp78 and caspase12 in 5 sections per animal ( $\times 200)$. Spinal cord sections were rinsed in $0.1 \mathrm{~mol} / \mathrm{L} \mathrm{PBS}$ for 20 minutes and blocked in 2\% normal horse serum for 2 hours at room temperature. Then they were incubated with primary antibodies in $10 \%$ normal horse serum or $10 \%$ normal rabbit serum and $0.3 \%$ Triton-X 100 for 20 hours at $4{ }^{\circ} \mathrm{C}$, respectively. The primary antibodies used were the same as those used for Western blot analysis noted previously, and each dilution was as follows: antibody against Grp78 at 1:200 and antibody against caspase12 at $1: 200$.

After endogenous peroxidase activity was quenched by exposing slides to $0.3 \% \mathrm{H}_{2} \mathrm{O}_{2}$ and $10 \%$ methanol for 20 minutes, the slides were washed in PBS and incubated for 3 hours with biotinylated antigoat IgG (PK-6105; Vector Laboratories, Burlingame,
Calif) and biotinylated antimouse IgG (PK-6102; Vector Laboratories) at 1:200 dilution in PBS containing $0.018 \%$ normal horse and rabbit serum, respectively. Subsequently they were incubated with avidin-biotin-horseradish peroxidase complex (PK-6102; Vector Laboratories). The slices were colorized with $\mathrm{DAB} / \mathrm{H}_{2} \mathrm{O}_{2}$ solution and cytoplasm, and counterstained with hematoxylin. To ascertain specific binding of antibody for the protein, a set of sections were stained in a similar way without the primary antibody.

\section{Fluorescence Double-Labeling Study for Grp78 and Caspase12}

Spinal cord sections were prepared as previously described. A nonspecific blocking procedure was performed with $10 \%$ horse serum before application of primary antibodies. Then the sections were incubated with Grp78 goat polyclonal antibodies 1:100 (Santa Cruz Biotechnology) simultaneously with caspase12. These primary antibodies were incubated overnight at $4{ }^{\circ} \mathrm{C}$ and detected by using donkey antimouse IgG linked with TexasRed 1:50 (715075-147, Jackson Immunoresearch, West Grove, Pa) and donkey antigoat IgG linked with fluorescein isothiocyanate 1:50 (705-095151, Jackson Immunoresearch). The slides were mounted in aqueous mounting media with DABCO and observed with fluorescein microscopy $(\times 200)$. We also examined the population of Grp78and caspase12-expressing cells in 5 sections per animals.

\section{Statistical Analysis}

Quantitative analyses of the neurologic score, cell numbers, and optical density of Western blots were analyzed by analysis of variance. Parametric data are present as mean \pm SD.

\section{Results}

\section{Neurologic Outcome}

In the sham control group $(\mathrm{n}=5)$, all rabbits were normal (grade 5). In the 15-minute ischemia group at 2 days after the procedure $(\mathrm{n}=5), 1$ rabbit $(20 \%)$ was normal (grade 5), 3 rabbits $(60 \%)$ had minimal ataxia (grade 4$)$, and 1 rabbit $(20 \%)$ had ataxia (grade 3 ). In the 15-minute ischemia group at 7 days after the procedure $(n=5), 2$ rabbits $(40 \%)$ did not hop (grade 2) and 3 rabbits (60\%) had ataxia (grade 3). There was a significant difference between the Johnson's neurologic scores at 2 days and 7 days after the procedure in the 15-minute ischemia group $(P=.0011)$. This difference was similar between the sham control group and the 15 minute ischemia group 7 days after the procedure $(P<$ .0001). Fifteen minutes of ischemia affected neuronal function.

\section{Histologic Study}

After sham control, no significant change was seen in motor neurons $(20.2 \pm 3.033)$. After 15 minutes of ischemia on the seventh day of reperfusion, approximately $70 \%$ of the motor neuron cells in ventral gray matter were lost $(8.4 \pm 2.793$, $P=.0002)$, although most motor neuron cells had remained intact after 2 days of reperfusion $(17.8 \pm 4.604, P=.0045)$. Small motor neurons and intermediate neurons survived the 
A

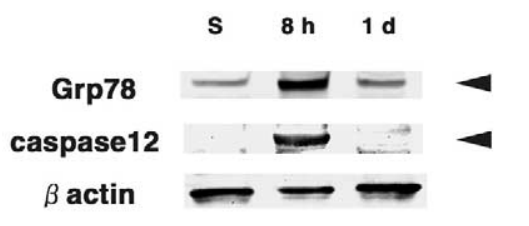

B

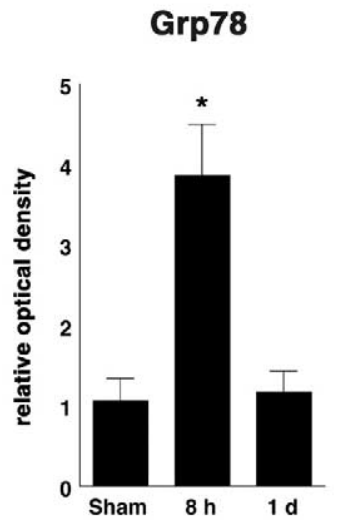

caspase12

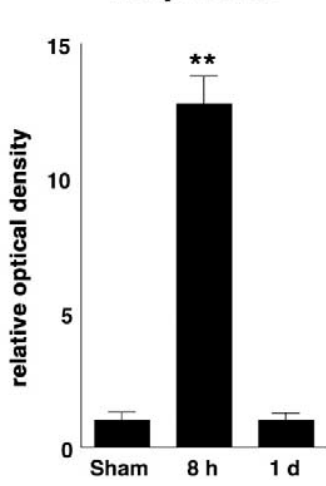

Figure 1. A, Representative Western blot for Grp78 and caspase12. Immunoreactivity was weakly (Grp78) or not (caspase12) detected in sham-controls. Strong bands were observed at the expected size (78 kD and 50 kD, respectively) 8 hours after blood flow restoration, but became less dense at 1 day. $\beta$-actin showed no change. B, Quantitative analysis showed that $\mathbf{1 5}$ minutes of ischemia significantly increased Grp78 and caspase12 at 8 hours of reperfusion $\left({ }^{*} P<.0001\right.$, ${ }^{*} P<.0001$ compared with sham control group and reperfusion at 1 day group).

ischemia. Dorsal horn neurons were intact after 15 minutes of ischemia (data not shown). The 15 minutes of ischemia 7 days after the procedure affected the number of motor neuronal loss cells in contrast with sham control.

Thus, selective loss of motor neurons was confirmed, in accordance with our previous reports. ${ }^{5}$

\section{Western Blot Analysis}

Representative results of Western blot analysis are shown in Figure 1. With antibody against Grp78, a weak band was detectable in samples of sham control, but those at 8 hours after blood flow restoration revealed a single band with a molecular weight of $78 \mathrm{kDa}$ (Figure 1, A). This band became scarcely detectable 1 day after reperfusion. With antibody against caspase 12, no band was detectable in samples of sham control, but those at 8 hours after blood flow restoration revealed a single band with molecular weight of $50 \mathrm{kDa}$ (Figure 1, A). This band became detectable 1 day after reperfusion and was almost lost at 2 days. The membrane without the primary antibody revealed no band (data not shown). With quantitative analysis, we found that Grp78

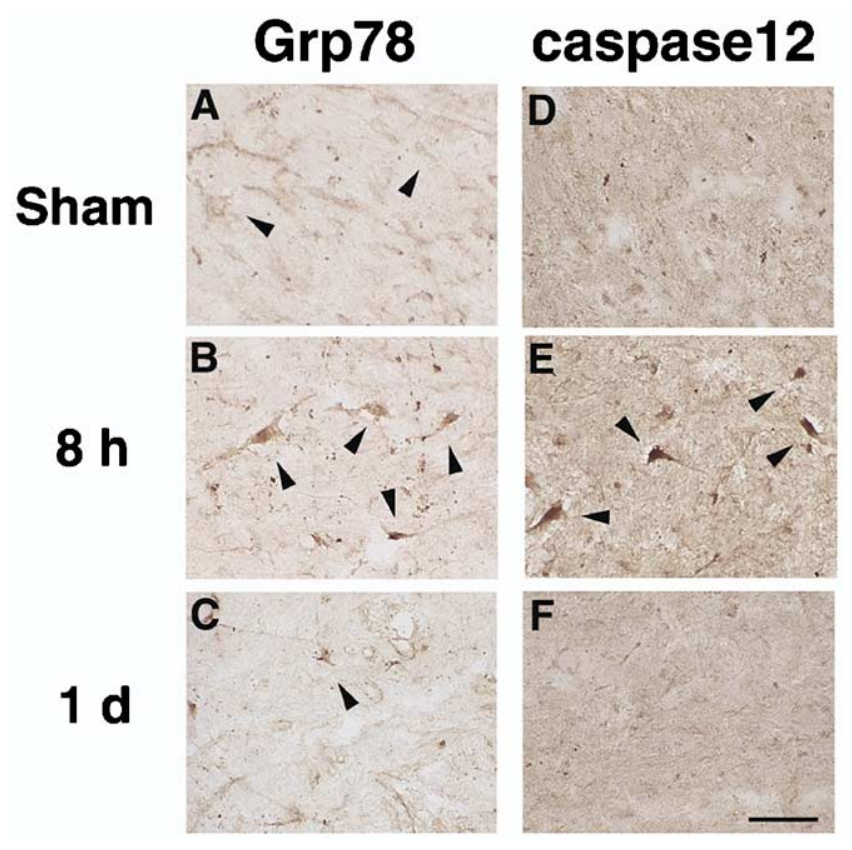

Figure 2. Immunostaining against Grp78 and caspase12 in motor neurons in a sham spinal cord $(A, D)$ at 8 hours $(B, E)$ and 1 day (C, F) of reperfusion. Motor neurons that express immunoreactive $\operatorname{Grp78}(\mathrm{A}, \mathrm{B}, \mathrm{C})$ and caspase12 (E) (arrowheads). Bar $=100 \mu \mathrm{m}$.

and caspase 12 were significantly increased at 8 hours of reperfusion $(* P<.0001, * * P<.0001$ ) (Figure $1, B)$.

\section{Histochemical Study}

Immunoreactive Grp78 and caspase12 of sections from spinal cords are shown in Figure 2. The spinal cords of animals in the sham control group at 8 hours and 7 days of reperfusion did not show Grp78 (Figure 2, A) and caspase12 (Figure 2, E) immunoreactivities in any cells. Motor neurons selectively showed strong immunoreactivity for Grp78 (Figure 2, B) and caspase12 (Figure 2, F) at 8 hours of reperfusion. Immunoreactivity of motor neuron cells for Grp78 (Figure 2, C) and antigen was almost lost in the motor neurons at 1 day. Immunoreactivity of motor neuron cells for caspase 12 decreased at 1 day (Figure 2) and was almost lost in the motor neurons at 2 days (Figure 2).

\section{Fluorescence Double-Labeling Study}

The results of Grp78 and caspase12 double-staining immunohistochemistry are shown in Figure 3. Grp78 positive neurons $(18.2 \pm 3.114 /$ ventral horn, mean $\pm \mathrm{SD})$ were strongly co-localized with caspase 12 positive neurons (18.0 $\pm 2.345 /$ ventral horn) at only 8 hours of reperfusion. Furthermore, approximately $85 \%$ of motor neurons (15.7 \pm 1.643/ventral horn) expressed both Grp78 and caspase12. 

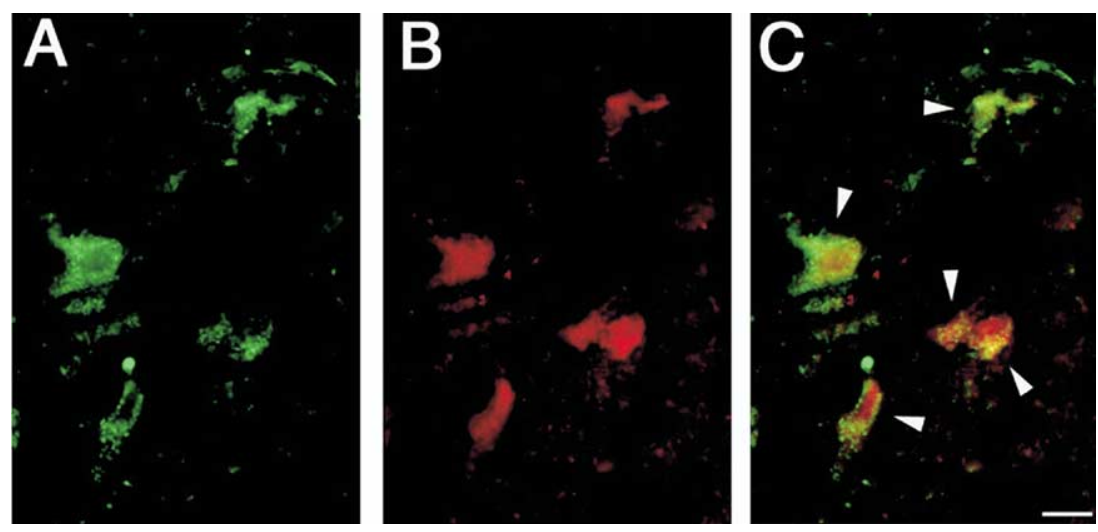

Figure 3. Colocalization of Grp78 and caspase12 in motor neurons 8 hours after ischemia. A, Grp78 was detected by fluorescein isothiocyanate (green). B, Caspase12 was detected by Texas red (red). C, Merged image with double positive (arrowheads) as yellow color. Bar $=\mathbf{5 0} \boldsymbol{\mu m}$.

\section{Discussion}

We demonstrate a temporal association between induction of Grp78 and caspase 12 at 8 hours after transient spinal cord ischemia in rabbits; however, the mechanism of neuronal cell death remains unclear. Until recently, the physiologic role of the ER was thought to be limited to calcium storage and the folding and processing of newly synthesized proteins. Conditions such as glucose deprivation, alterations in calcium homeostasis, and free radical exposure lead to the accumulation of malfolded proteins in the ER, causing ER stress. ${ }^{14}$ Under the condition of ER stress, 3 different mechanisms are known to be activated: transcriptional induction of ER resident chaperones, translational attenuation of misfolded or unfolded proteins, and degradation of these proteins through the ubiquitin proteasome system. ${ }^{15}$ It has only just been appreciated that ER stress may also lead to apoptosis. ${ }^{16}$

Grp78 is known to act as molecular chaperone, regulate protein folding, and facilitate protein translocation in ER and ultimately protein secretion. ${ }^{17}$ Grp78 levels were shown to increase after exposure to agents that elevate intracellular calcium level (eg, calcium inophores). ${ }^{18}$ Perturbations of ER function appear to act as an early stage of cell death process before disruption of cellular calcium homeostasis. Stabilization of cellular calcium homeostasis may also play a neuroprotective role because elevation of intracellular calcium level is implicated in the neurotoxic mechanism of glutamate excitoxicity ${ }^{19}$ and oxidative stress. ${ }^{20} \mathrm{~A}$ pivotal role for events occurring in the ER in the neuronal death process is becoming increasingly appreciated. In neurons, $\mathrm{Ca}^{2+}$ release from ER contribute to excitotoxic cell death because blocking calcium release from ER can protect neurons from excitotoxicity. ${ }^{21}$ In addition, the anti-apoptotic protein Bcl-2 may protect cells against apoptosis by stabilizing ER calcium homeostasis. ${ }^{22}$ An important role for Grp78 in stabilizing ER $\mathrm{Ca}^{2+}$ homeostasis was also indicated: Grp78 overexpression inhibited the increase in intracellular calcium typically induced by $\mathrm{H}_{2} \mathrm{O}_{2}$. Recently, $\mathrm{Yu}$ et $\mathrm{al}^{20}$ reported that suppression of Grp78 expression enhances apoptosis and disruption of cellular calcium homeostasis in hippocampal neurons exposed to excitotoxic and oxidative insults. Furthermore, Aoki et $\mathrm{al}^{23}$ reported that reduction of Grp78 expression allows hippocampal neuronal death after transient ischemia in gerbil brain. In this study, Grp78 was induced in motor neurons at 8 hours of reperfusion, which returned to the baseline level at 1 day. The selective induction of Grp78 in motor neuron cells may indicate ER stress that occurs in the spinal cord after 15 minutes of ischemia. Finally, almost all motor neurons may be selectively damaged after 7 days of reperfusion. Therefore, the mechanism of induction of Grp78 may be similar to the motor neuron cells in the spinal cord and hippocampus of the brain.

To date, 14 caspases have been activated in a way similar to that in which the clotting and complement cascades have been discovered. Caspase9, an initiator caspase, is responsible for the activation of many of the downstream caspases and is considered to reside at the apex of this caspase cascade. ${ }^{24}$ Effector caspases, such as caspase 3 , carry out the actual dismantling of the cell. ${ }^{25}$ After the appropriate stress signal, caspase 12 is not only activated within the ER but also translocated from the ER membrane to the cytosol, where it can activate caspase9 in a noncytochrome-c-dependent manner. ${ }^{26}$ One of the potential mechanisms by which the ER contribute to apoptosis is through the activation of caspase 12 . Caspase 12 is a member of the interleukin- $1 \beta$-converting enzyme subfamily of caspases and is expressed universally in mouse tissues. ${ }^{13}$ It has been shown that caspase 12 is localized to the ER and activated by ER stress. ${ }^{27}$ It has also been shown that the treatment of cells with brefeldin-A or thapsigargin, both of which stimulate ER stress, will induce the expression of caspase $12 .{ }^{26}$ Conversely, apoptosis that occurs as a result of membrane- or mitochondrial-targeted signals does not activate caspase $12 .{ }^{13,28} \mathrm{~A}$ recent study showed that caspase12 
was activated in neurons on the ischemic side at 5 to 23 hours of reperfusion after a transient 60 minutes of middle cerebral artery occlusion in mouse brain. ${ }^{29}$ Furthermore, Shibata et $\mathrm{al}^{29}$ also demonstrated that many caspase 12 positive neurons exhibited DNA fragmentation detected by the terminal deoxynucleotide transferasemediated dUTP nick-end labeling method. These results suggest that the activate caspase 12 was likely to contribute to neuronal death from ischemia-reperfusion. In this study, caspase 12 was induced at 8 hours of reperfusion in motor neurons that eventually die. Therefore, the mechanism of induction of caspase 12 may be similar to the motor neuron cells in the spinal cord and brain.

A recent study showed that the overexpression of Grp78 was observed in the motor neurons of the spinal cord before onset of amyotrophic lateral sclerosis in transgenic mice with SOD1 mutation. ${ }^{30}$ In this study, the increase in the immunoreactivity of Grp78 was demonstrated selectively in ventral motor neuron cells in the spinal cord after 8 hours of reperfusion. This finding suggests that the oxidative injury could activate cytokines and augment Grp78 induction as a compensatory mechanism. Therefore, our results suggest that the mechanism of motor neuron death in the spinal cord after ischemia might have a feature similar to that of amyotrophic lateral sclerosis.

This study also demonstrates that immunoreactivities for both Grp78 and caspase 12 were induced at 8 hours in the same motor neurons that eventually die. These results suggest that ER stress was induced in motor neurons and contributed to neuronal death by transient spinal cord ischemia in rabbits.

\section{References}

1. Cambria RP, Clouse WD, Davidson JK, Dunn PF, Corey M, Dorer D. Thoracoabdominal aneurysm repair: results with 337 operations performed over a 15-year interval. Ann Surg. 2002;236:471-9.

2. Livesay JJ, Cooley DA, Ventemiglia RA, Montero CG, Warrian RK, Brown DM, et al. Surgical experience in descending thoracic aneurysmectomy with and without adjuncts to avoid ischemia. Ann Thorac Surg. 1985;39:37-46.

3. Matsui Y, Goh K, Shiiya N, Murashita T, Miyama M, Ohba J, et al. Clinical application of evoked spinal cord potentials elicited by direct stimulation of the cord during temporary occlusion of the thoracic aorta. J Thorac Cardiovasc Surg. 1994;107:1519-27.

4. Moore WM, Hollier LY. The influence of severity of spinal cord ischemia in the etiology of delayed-onset paraplegia. Ann Surg. 1991; 213:427-32.

5. Sakurai M, Nagata T, Abe K, Horinouchi T, Itoyama Y, Tabayashi K. Survival- and death promoting events after transient spinal cord ischemia in rabbits: induction of Akt and caspase 3 in motor neurons. J Thorac Cardiovasc Surg. 2003;125:370-7.

6. Yuan J, Yankner BA. Apoptosis in the nervous system. Nature. 2000; 407:802-9.

7. Eldadah BA, Fadden AI. Caspase pathways, neuronal apoptosis an CNS injury. J Neurotrauma. 2000;17:811-29.

8. Ferri KF, Kroemer G. Organelle-specific initiation of the cell death pathways. Nat Cell Biol. 2001;3:E255-63.

9. Mancini M, Machamer CE, Roy S, Nicholson DW, Thornberr NA, Casciola-Rosen LA, et al. Caspase-2 is localized at the Golgi complex and cleaves golgin-160 during apoptosis. J Cell Biol. 2000;149:603-12.
10. Paschen W, Doutheil J. Disturbances of the functioning of endoplasmic reticulum: a key mechanism underlying neuronal injury. $J$ Cereb Blood Flow Metab. 1999;19:1-18.

11. DeGarcia DJ, Kumar R, Owen CR, Krause GS, White BC. Molecular pathway of protein synthesis inhibition during brain reperfusion: implication for neuronal survival or death. J Cereb Blood Flow Metab. 2002;22:127-41.

12. Ma Y, Hendershot LM. The unfolding tale of the unfolded protein response. Cell. 2001;107:827-30.

13. Nakagawa T, Zhu H, Morishima N, Li E, Xu J, Yanker BA, et al. Caspase-12 mediates endoplasmic reticulum-specific apoptosis and cytotoxicity by amyloid- $\beta$. Nature. 2000;403:98-103.

13a.Johnson SH, Kraimer JM, Graeber GM. Effects of flunarizine on neurological recovery and spinal cord blood flow in experimental spinal cord ischemia in rabbits. Stroke. 1993;24:1547-53.

14. Kaufman RJ. Stress signaling from the lumen of the endoplasmic reticulum: coordination of gene transcriptional and translational controls. Gene Dev. 1999;13:1211-33.

15. Mori K. Triparite management of unfolded protein in the endoplasmin reticulum. Cell. 2000;101:451-4.

16. Welihinda AA, Tirasophon W, Kaufman RJ. The cellular response to protein misfolding in the endoplasmic reticulum. Gene Expr. 1999;7: 293-300.

17. Liang P, MacRae TH. Molecular chaperones and the cytoskeleton. J Cell Sci. 1997;110:1431-40.

18. Lee AS. Coordinated regulation of a set of genes by glucose and calcium ionophores in mammalian cells. Trends Biochem Sci. 1987; 12:20-9.

19. Mattson MP, Mark RJ. Excitotoxicity and neuroprotection in vitro. Adv Neurol. 1996;71:1-30.

20. Yu ZW, Lou H, Fu W, Mattson MP. The endoplasmic reticulum stress-responsive protein GRP78 protects neurons against excitotoxicity and apoptosis: suppression of oxidative stress and stabilization of calcium homeostasis. Exp Neurol. 1999;155:302-14.

21. Frandsen A, Schousboe A. Dantrolene prevent glutamate cytotoxicity and $\mathrm{Ca}^{2+}$ release from intracellular store in cultured cerebral cortical neurons. J Neurochem. 1991;56:1075-8.

22. Lam M, Dubyak G, Chen L, Nunez G, Meisfeld RL, Distelhorst CW. Evidence that $\mathrm{Bcl}-2$ repress apoptosis by regulating endoplasmic reticulum-associated $\mathrm{Ca}^{2+}$ fluxes. Proc Natl Acad Sci U S A. 1994;91: 6569-73.

23. Aoki M, Tamatani M, Taniguchi M, Yamaguchi A, Bando Y, Kasai K, et al. Hypothermic treatment restores glucose regulated protein 78 (GRP78) expression in ischemic brain. Mol Brain Res. 2001;95:117-28.

24. Slee EA, Harte MT, Kluck RM, Wolf BB, Casiano CA, Newmeyer $\mathrm{DD}$, et al. Ordering the cytochrome c-initiated caspase cascade: hierarchical activation of caspases-2, -3, -6, -7, -8, and -10 in a caspase9-dependent manner. J Cell Biol. 1999;144:281-92.

25. Danie PT. Dissecting the pathways to death. Leukemia. 2000;14:2035-44.

26. Rao RV, Hermel E, Castro-Obregon S, del Rio G, Ellerby LM, Ellerby $\mathrm{HM}$, et al. Coupling endoplasmic reticulum stress to the cell death program. Mechanism of caspase activation. J Biol Chem. 2001;276: 33869-74.

27. Yoneda T, Imaizumi K, Oono K, Yui D, Gomi F, Katayama T, et al. Activation of caspase-12, an endoplastic reticulum (ER) resident caspase, through tumor necrosis factor receptor-associated factor 2-dependent mechanism in response to the ER stress. J Biol Chem. 276: 13935-40.

28. Nakagawa T, Yuan J. Cross-talk between two cysteine protease families. Activation of caspase-12 by calpain in apoptosis. J Cell Biol. 150:887-94.

29. Shibata M, Hattori H, Sasaki T, Gotoh J, Hamada J, Fukuuchi Y. Activation of caspase- 12 by endoplasmic reticulum stress induced by transient middle cerebral artery occlusion in mice. Neuroscience. 2003;118:491-9.

30. Tobisawa S, Hozumi Y, Arawaka S, Koyama S, Wada M, Nagai M, et al. Mutant SOD1 linked to familial amyotrophic lateral sclerosis, but not wild-type SOD1, induces ER stress in COS7 cells and transgenic mice. Biochem Biophys Res Commun. 2003;303:496503. 